\title{
ALDECALMYCIN, A NEW ANTIMICROBIAL ANTIBIOTIC FROM Streptomyces
}

\section{STRUCTURE ELUCIDATION BY NMR STUDIES}

\author{
Ryuichi Sawa, Yoshikazu Takahashi, Tsutomu Sawa, \\ Hiroshi Naganawa and Tomio Takeuchi \\ Institute of Microbial Chemistry, \\ 3-14-23 Kamiosaki, Shinagawa-ku, Tokyo 141, Japan
}

(Received for publication June 30, 1994)

\begin{abstract}
A new antibiotic, aldecalmycin (1) was isolated from the culture broth of Streptomyces sp. MJ147-72F6. The ${ }^{1} \mathrm{H}$ and ${ }^{13} \mathrm{C}$ NMR spectra of 1 were complicated due to the presence of a $\beta$-ketoaldehyde moiety. Therefore, 1 was converted into an ethylene ketal derivative (2) and into a dihydroaldecalmycin (3). These derivatives gave assignable NMR spectra. The planar structure was elucidated by using ${ }^{1} \mathrm{H}^{1} \mathrm{H}$ COSY, 2D-HOHAHA, ${ }^{1} \mathrm{H}^{13} \mathrm{C}$ COSY and HMBC spectra of 2 . The conformation of the decalin ring was elucidated by using 1D-HOHAHA, NOE difference and NOESY spectra of 3 . The geometry of double bond in the side chain was determined by NOE difference and NOESY spectra of 3 .
\end{abstract}

In the course of screening soil microorganisms for their ability to produce new antibiotics, we have found aldecalmycin (1), from a culture broth of Streptomyces sp. MJ147-72F6. In the preceding paper ${ }^{1)}$, taxonomy, production, fermentation, isolation, physico-chemical and biological properties of aldecalmycin were reported. In this paper, we describe the structure elucidation of aldecalmycin (Fig. 1).

\section{Results and Discussion}

The ${ }^{1} \mathrm{H}$ NMR spectrum of aldecalmycin was complicated in the various solvents due to a keto-enol tautomerism ${ }^{1)}$. Therefore, we synthesized some aldehyde-masked derivatives to obtain assignable NMR spectra. The ethylene ketal derivative (2) and the cyanoborohydride reduction product, dihydroaldecalmycin (3), were readily obtained and used to elucidate the planar structure and the relative stereochemistry, respectively.

\section{Planar Structure of Compound 2}

Treatment of 1 with ethylene glycol and D-camphorsulfonic acid in dioxane at $22^{\circ} \mathrm{C}$ for 23 hours gave ethylene ketal derivative (2). Physico-chemical properties of 2 are shown in Table 1. The molecular formula of 2 was determined as $\mathrm{C}_{35} \mathrm{H}_{58} \mathrm{O}_{10}$ by HRFAB-MS. The ${ }^{1} \mathrm{H}$ NMR spectrum of 2 is shown in Fig. 2 and the ${ }^{13} \mathrm{C}$ and ${ }^{1} \mathrm{H}$ NMR data of 2 are summarized in Table 2. All one bond connections

Fig. 1. Structures of aldecalmycin (1) and its derivatives $(\mathbf{2}, \mathbf{3})$.

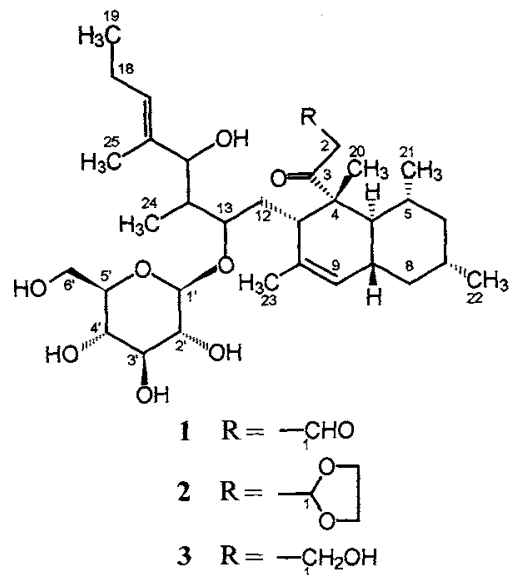


Table 1. Physico-chemical properties of aldecalmycin (1), ethylene ketal derivative (2) and dihydroaldecalmycin (3).

\begin{tabular}{|c|c|c|c|}
\hline & 1 & 2 & 3 \\
\hline Appearance & White powder & White powder & White powder \\
\hline $\mathrm{MP}\left({ }^{\circ} \mathrm{C}\right)$ & $125 \sim 128$ & $113 \sim 117$ & $124 \sim 127$ \\
\hline Optical rotation $[\alpha]_{D}$ & $\begin{array}{l}-78.7^{\circ}\left(26^{\circ} \mathrm{C}, c 1.0\right. \\
\mathrm{MeOH})\end{array}$ & $\begin{array}{l}-73.6^{\circ}\left(26^{\circ} \mathrm{C}, c 1.0\right. \\
\mathrm{MeOH})\end{array}$ & $\begin{array}{l}-65.3^{\circ}\left(23^{\circ} \mathrm{C}, c 0.27\right. \\
\mathrm{MeOH})\end{array}$ \\
\hline Molecular formula & $\mathrm{C}_{33} \mathrm{H}_{54} \mathrm{O}_{9}$ & $\mathrm{C}_{35} \mathrm{H}_{58} \mathrm{O}_{10}$ & $\mathrm{C}_{33} \mathrm{H}_{56} \mathrm{O}_{9}$ \\
\hline \multicolumn{4}{|l|}{ Elemental analysis } \\
\hline Calcd: & $\begin{array}{c}\mathrm{C} 65.64, \mathrm{H} 9.18, \text { O } 25.18 \\
\left(\text { as } \mathrm{C}_{33} \mathrm{H}_{54} \mathrm{O}_{9} \cdot \frac{1}{2} \mathrm{H}_{2} \mathrm{O}\right)\end{array}$ & & $\begin{array}{l}\mathrm{C} 65.43, \mathrm{H} 9.48 \\
\quad\left(\text { as } \mathrm{C}_{33} \mathrm{H}_{56} \mathrm{O}_{9} \cdot \frac{1}{2} \mathrm{H}_{2} \mathrm{O}\right)\end{array}$ \\
\hline Found: & C 65.48, H 9.29, O 25.47 & & C 65.51, H 9.47 \\
\hline FAB-MS $(m / z)$ & $593(\mathrm{M}-\mathrm{H})^{-}$ & $637(\mathrm{M}-\mathrm{H})^{-}$ & $619(\mathrm{M}+\mathrm{Na})^{+}$ \\
\hline \multicolumn{4}{|l|}{ HRFAB-MS $(m / z)$} \\
\hline Calcd: & 593.3689 (as $\mathrm{C}_{33} \mathrm{H}_{53} \mathrm{O}_{9}$ ) & 637.3952 (as $\mathrm{C}_{33} \mathrm{H}_{57} \mathrm{O}_{10}$ ) & 619.3822 (as $\mathrm{C}_{33} \mathrm{H}_{56} \mathrm{O}_{9} \mathrm{Na}$ ) \\
\hline Found: & $593.3687(\mathrm{M}-\mathrm{H})^{-}$ & $637.3935(\mathrm{M}-\mathrm{H})^{-}$ & $619.3825(\mathrm{M}+\mathrm{Na})^{+}$ \\
\hline \multicolumn{4}{|l|}{$\mathrm{UV} \lambda_{\max } \mathrm{nm}\left(\mathrm{E}_{1}^{1 \%} \mathrm{~cm}\right)$} \\
\hline in $\mathrm{MeOH}$ & $272(30), 299(31)$ & End absorption & End absorption \\
\hline in $\mathrm{HCl}-\mathrm{MeOH}$ & $271(24), 303(\mathrm{sh}, 13)$ & & \\
\hline in $\mathrm{NaOH}-\mathrm{MeOH}$ & $304(395)$ & & \\
\hline $\mathrm{IR} v \max \left(\mathrm{cm}^{-1}\right) \mathrm{KBr}$ & $\begin{array}{l}3430,2960,2910,1694 \\
1626,1456,1379,1074 \\
1038,995\end{array}$ & $\begin{array}{l}3440,2960,2910,1698 \\
1636,1456,1379,1134 \\
1076,1019\end{array}$ & $\begin{array}{l}3420,2960,2910,1700 \\
1460,1380,1080,1040 \\
1020,1000\end{array}$ \\
\hline TLC (Rf value $)^{a}$ & 0.39 & 0.46 & 0.38 \\
\hline
\end{tabular}

a Silica gel TLC (Merck Art. 5715): $\mathrm{CHCl}_{3}-\mathrm{MeOH}(20: 3)$.

Fig. 2. ${ }^{1} \mathrm{H}$ NMR spectrum of 2 in $\mathrm{CD}_{3} \mathrm{OD}-\mathrm{C}_{6} \mathrm{D}_{6}(10: 1)(400 \mathrm{MHz})$.

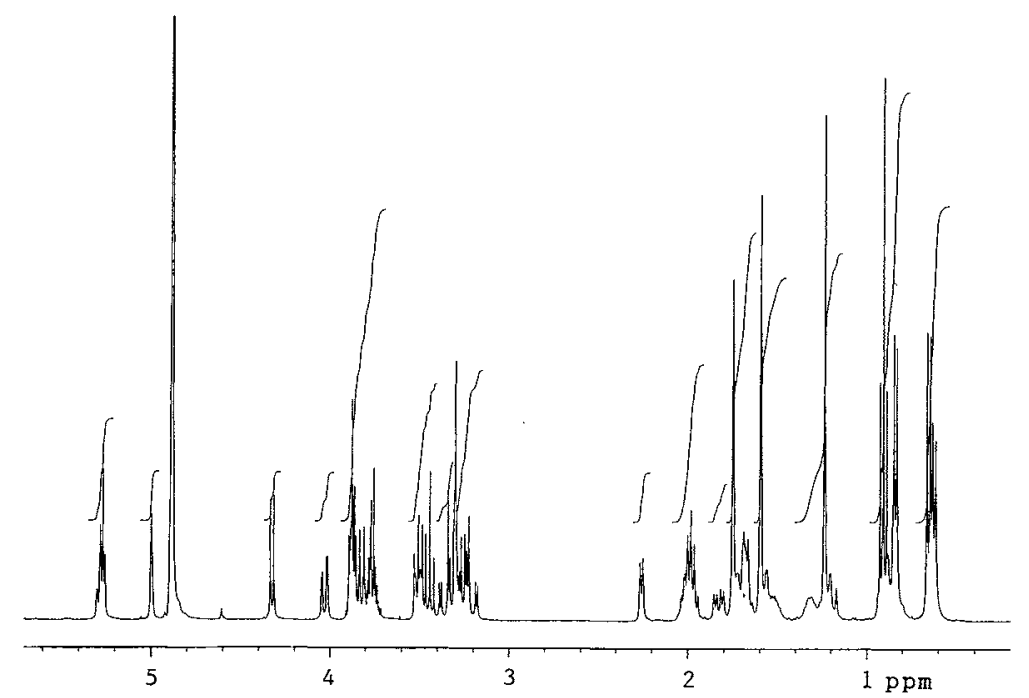

between ${ }^{1} \mathrm{H}$ and ${ }^{13} \mathrm{C}$ were elucidated by the ${ }^{1} \mathrm{H}^{13} \mathrm{C}$ COSY experiment. The NMR data and the molecular formula indicated the presence of seven methyls, eight methylenes, fourteen $\mathrm{sp}^{3}$ methines and two $\mathrm{sp}^{2}$ methines, four quaternary carbons and five exchangeable hydroxyl groups in compound 2.

The ${ }^{1} \mathrm{H}-{ }^{1} \mathrm{H}$ COSY spectrum of 2 revealed four partial structures shown in Fig. 3. The partial structure from C-1' to C-6' suggested an existence of a sugar. This sugar should be $\beta$-glucopyranoside type because four vicinal coupling constants were all large (A). The characteristic signals at $\delta 3.78$ and 3.89 , which were 
Table 2. ${ }^{13} \mathrm{C}$ and ${ }^{1} \mathrm{H}$ NMR data of 2 and 3.

(2)

(3)

\begin{tabular}{|c|c|c|c|c|c|c|}
\hline \multirow{2}{*}{ Position } & & \\
\hline & ${ }^{13} \mathrm{C}$ & ${ }^{1} \mathrm{H}$ (multiplicity) & $J$ value $(\mathrm{Hz})$ & ${ }^{13} \mathrm{C}$ & ${ }^{1} \mathrm{H}$ (multiplicity) & $J$ value $(\mathrm{Hz})$ \\
\hline \multirow[t]{2}{*}{1} & 102.0 & $5.28(\mathrm{t})$ & $J=4.8$ & 57.5 & $3.65(\mathrm{dt})$ & $J=4.8,11.3$ \\
\hline & & & & & $3.92(\mathrm{ddd})$ & $J=4.5,7.8,11.3$ \\
\hline \multirow[t]{2}{*}{2} & 45.6 & $3.22(\mathrm{dd})$ & $J=4.8,19.2$ & 43.8 & $2.89(\mathrm{ddd})$ & $J=4.5,4.8,19.2$ \\
\hline & & 3.37 (dd) & $J=4.8,19.2$ & & $3.13(\mathrm{ddd})$ & $J=4.8,7.8,19.2$ \\
\hline 3 & 214.7 & & & 216.3 & & \\
\hline 4 & 52.8 & & & 52.6 & & \\
\hline $4 a$ & 46.1 & $1.68(\mathrm{~m})$ & & 46.3 & $1.61(\mathrm{~m})$ & \\
\hline 5 & 38.0 & $1.33(\mathrm{~m})$ & & 38.2 & $1.39(\mathrm{~m})$ & \\
\hline \multirow[t]{2}{*}{6} & 47.5 & $0.91(\mathrm{~m})$ & & 47.8 & $0.95(\mathrm{~m})$ & \\
\hline & & $1.59(\mathrm{~m})$ & & & $1.65(\mathrm{~m})$ & \\
\hline 7 & 34.5 & $1.54(\mathrm{~m})$ & & 34.8 & $1.60(\mathrm{~m})$ & \\
\hline \multirow[t]{2}{*}{8} & 43.6 & $0.84(\mathrm{~m})$ & & 43.9 & $0.86(\mathrm{~m})$ & \\
\hline & & $1.74(\mathrm{~m})$ & & & $1.75(\mathrm{~m})$ & \\
\hline $8 \mathrm{a}$ & 42.4 & $1.68(\mathrm{~m})$ & & 42.6 & $1.73(\mathrm{~m})$ & \\
\hline 9 & 124.1 & $5.01(\mathrm{brs})$ & & 124.3 & 4.99 (brs) & \\
\hline 10 & 137.1 & & & 137.5 & & \\
\hline 11 & 45.1 & $2.27(\mathrm{brd})$ & $J=6.4$ & 45.5 & $2.11(\mathrm{brd})$ & $J=6.2$ \\
\hline \multirow[t]{2}{*}{12} & 32.3 & $1.21(\mathrm{dd})$ & $J=12.6,14.8$ & 32.3 & $1.07(\mathrm{dd})$ & $J=11.8,15.2$ \\
\hline & & $1.84(\mathrm{dd})$ & $J=6.4,14.8$ & & 1.79 (ddd) & $J=1.5,6.2,15.2$ \\
\hline 13 & 78.1 & $3.52(\mathrm{~m})$ & & 76.7 & 3.55 (ddd) & $J=1.5,2.7,11.8$ \\
\hline 14 & 40.9 & $2.03(\mathrm{ddq})$ & $J=3.0,6.6,10.4$ & 39.7 & $1.95(\mathrm{ddq})$ & $J=2.7,7.1,10.0$ \\
\hline 15 & 80.2 & 3.83 (d) & $J=10.4$ & 80.4 & 3.77 (d) & $J=10.0$ \\
\hline 16 & 136.0 & & & 136.5 & & \\
\hline 17 & 131.1 & $5.29(\mathrm{brt})$ & $J=7.4$ & 131.2 & $5.40(\mathrm{brt})$ & $J=7.6$ \\
\hline 18 & 21.6 & 1.99 (quintet) & $J=7.4$ & 21.7 & 2.06 (quintet) & $J=7.6$ \\
\hline 19 & 14.3 & $0.92(\mathrm{t})$ & $J=7.4$ & 14.3 & $0.99(\mathrm{t})$ & $J=7.6$ \\
\hline 20 & 17.5 & $1.25(\mathrm{~s})$ & & 17.4 & $1.24(\mathrm{~s})$ & \\
\hline 21 & 24.1 & $0.63(\mathrm{~d})$ & $J=7.0$ & 23.8 & 0.59 (d) & $J=6.8$ \\
\hline 22 & 22.7 & 0.85 (d) & $J=6.0$ & 22.7 & 0.92 (d) & $J=6.3$ \\
\hline 23 & 22.6 & $1.76(\mathrm{brs})$ & & 22.8 & $1.71(\mathrm{brs})$ & \\
\hline 24 & 10.6 & $0.66(\mathrm{~d})$ & $J=6.6$ & 10.4 & $0.60(\mathrm{~d})$ & $J=7.1$ \\
\hline 25 & 10.5 & $1.61(\mathrm{brs})$ & & 10.4 & $1.58(\mathrm{brs})$ & \\
\hline $1^{\prime}$ & 101.7 & 4.33 (d) & $J=8.2$ & 100.5 & 4.28 (d) & $J=7.6$ \\
\hline $2^{\prime}$ & 75.1 & 3.25 (dd) & $J=8.2,9.0$ & 75.4 & 3.15 (dd) & $J=7.6,8.9$ \\
\hline $3^{\prime}$ & 78.1 & $3.45(\mathrm{t})$ & $J=9.0$ & 78.3 & $3.35(\mathrm{dd})$ & $J=8.5,8.9$ \\
\hline $4^{\prime}$ & 71.6 & $3.51(\mathrm{t})$ & $J=9.0$ & 72.0 & $3.24(\mathrm{dd})$ & $J=8.5,9.6$ \\
\hline $5^{\prime}$ & 77.3 & $3.3^{* 1}$ & & 78.2 & $3.3^{* 1}$ & \\
\hline \multirow[t]{2}{*}{$6^{\prime}$} & 62.4 & $3.88(\mathrm{dd})$ & $J=4.6,12.0$ & 63.2 & $3.69(\mathrm{dd})$ & $J=5.6,11.5$ \\
\hline & & $4.04(\mathrm{dd})$ & $J=3.2,12.0$ & & $3.96(\mathrm{dd})$ & $J=1.8,11.5$ \\
\hline Ketal 1 & 65.5 & $3.78(\mathrm{~m})^{* 2}$ & & & & \\
\hline Ketal 2 & 65.7 & $3.89(\mathrm{~m})^{* 2}$ & & & & \\
\hline
\end{tabular}

(2): $400 \mathrm{MHz}\left({ }^{1} \mathrm{H}\right)$ and $100 \mathrm{MHz}\left({ }^{13} \mathrm{C}\right)$ in $\mathrm{CD}_{3} \mathrm{OD}-\mathrm{C}_{6} \mathrm{D}_{6}(10: 1)$.

(3): $270 \mathrm{MHz}\left({ }^{1} \mathrm{H}\right)$ and $67.5 \mathrm{MHz}\left({ }^{13} \mathrm{C}\right)$ in $\mathrm{CD}_{3} \mathrm{OD}$.

Chemical shifts in ppm from TMS as an internal standard.

${ }^{* 1}$ Partially obscured by the solvent signal. ${ }^{* 2}$ These values may be interchanged.

coupled with each other, were assigned to an oxygen bearing methylene. The signal at $\delta 5.28$ was assigned to the methine proton, $1-\mathrm{H}$ attached to a carbon bearing two oxygens. This proton was coupled to the methylene protons, $2-\mathrm{H}$. These signals were assignable to the newly constrained ketal moiety (B). The partial structures of the unsaturated alkyl chain (C) and the saturated alkyl chain (D) were also deduced from the ${ }^{1} \mathrm{H}-{ }^{1} \mathrm{H}$ COSY spectrum. 
Fig. 3. Partial structures (A, B, C and D) of 2 by ${ }^{1} \mathrm{H}^{-1} \mathrm{H}$ COSY

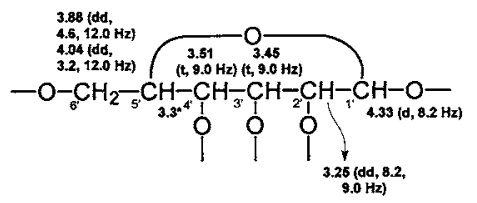

(A) * Partially obscured by the solvent signal.

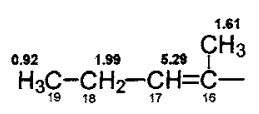

(C)

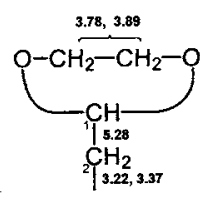

(B)

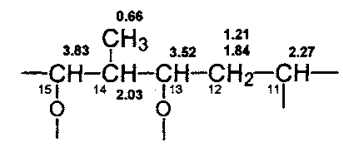

(D)

The partial structure (E), which was composed by many overlapping signals $(\delta 0.8 \sim 1.8)$ was determined by two dimensional homonuclear Hartmann-Hahn (2D-HOHAHA) ${ }^{2)}$ and heteronuclear multiple-bond correlation $(\mathrm{HMBC})^{3)}$ experiments. The 2D-HOHAHA spectrum revealed the connectivities from $4 \mathrm{a}-\mathrm{H}$ to $23-\mathrm{H}$ as shown in Fig. 4 . The $\mathrm{HMBC}$ spectrum revealed the following two- and three-bonds connectivities between ${ }^{1} \mathrm{H}$ and ${ }^{13} \mathrm{C}$ :
Fig. 4. Partial structure (D $\sim$ E) of 2 by $2 \mathrm{D}-\mathrm{HOHAHA}$ and $\mathrm{HMBC}$.

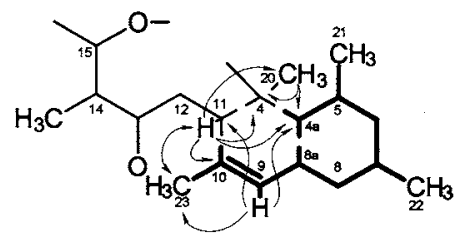

(D)

(E)

\section{- 2D-HOHAHA \\ $\frown \mathrm{HMBC}$}

Fig. 5. Connectivities among partial structures (A, B, C, D and E) by HMBC.

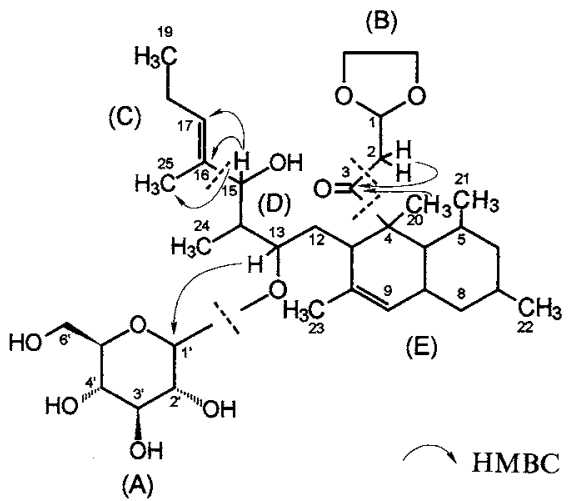
i) from 9-H $(\delta 5.01)$ to $\mathrm{C}-4 \mathrm{a}(\delta 46.1), \mathrm{C}-23(\delta 22.6)$ and $\mathrm{C}-11(\delta 45.1)$,
ii) from $11-\mathrm{H}(\delta 2.27)$ to $\mathrm{C}-10(\delta 137.1), \mathrm{C}-23, \mathrm{C}-4(\delta 52.8), \mathrm{C}-20(\delta 17.5)$ and $\mathrm{C}-4 \mathrm{a}$,
iii) from $23-\mathrm{H}(\delta 1.76)$ to $\mathrm{C}-11$,
iv) from $20-\mathrm{H}(\delta 1.25)$ to $\mathrm{C}-4$ and $\mathrm{C}-4 \mathrm{a}$.

Both spectral analyses indicated a substituted decalin ring possessing one double bond as shown in (E). Furthermore, the connectivity between (D) and (E) was established because $\mathrm{C}-11$ was common to both.

The connectivities of the five partial structures $(\mathrm{A} \sim \mathrm{E})$ were also elucidated by the HMBC spectrum. The following cross peaks between ${ }^{1} \mathrm{H}$ and ${ }^{13} \mathrm{C}$ showed the connectivities between each partial structure:

i) from $13-\mathrm{H}(\delta 3.52)$ to $\mathrm{C}-1^{\prime}(\delta 101.7)$; (A)-(D),

ii) from $15-\mathrm{H}(\delta 3.83)$ to $\mathrm{C}-16(\delta 136.0), \mathrm{C}-17(\delta 131.1)$, and C-25 $(\delta 10.5)$; (C)-(D),

iii) from both $2-\mathrm{H}(\delta 3.22,3.37)$ and $20-\mathrm{H}$ to the carbonyl $\mathrm{C}-3(\delta 214.7)$; (B)-(E).

From these results, all connectivities of the partial structures were clarified as shown in Fig. 5. Five exchangeable hydroxyl groups should be connected to $\mathrm{C}-2^{\prime}, \mathrm{C}-3^{\prime}, \mathrm{C}-4^{\prime}, \mathrm{C}-6^{\prime}$ (sugar moiety) and C-15 by considering the molecular formula. Thus, the planar structure of 2 was determined and the structure of aldecalmycin (1) followed with C-1 of the ethylene ketal moiety of 2 being replaced with an aldehyde group.

\section{Relative Stereochemistry of the Decalin Ring}

The relative stereochemistry of the decalin ring was studied by spectral analyses of dihydroaldecalmycin (3) which was synthesized by reduction of 1 with sodium cyanoborohydride. Physico-chemical properties of 3 are shown in Table 1. The molecular formula of 3 was determined as $\mathrm{C}_{33} \mathrm{H}_{56} \mathrm{O}_{9}$ by HRFAB-MS and 
Fig. 6. 1D-HOHAHA spectrum of 3 irradiating at $\delta 0.59(21-\mathrm{H})(400 \mathrm{MHz})$.

1D-HOHAHA spectrum

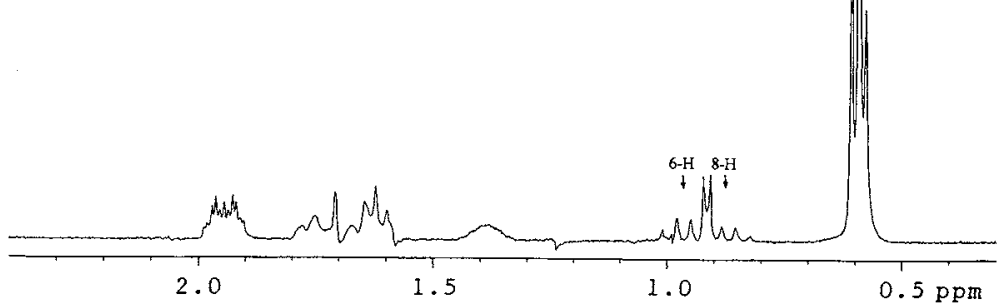

Normal ${ }^{1} \mathrm{H}$ spectrum

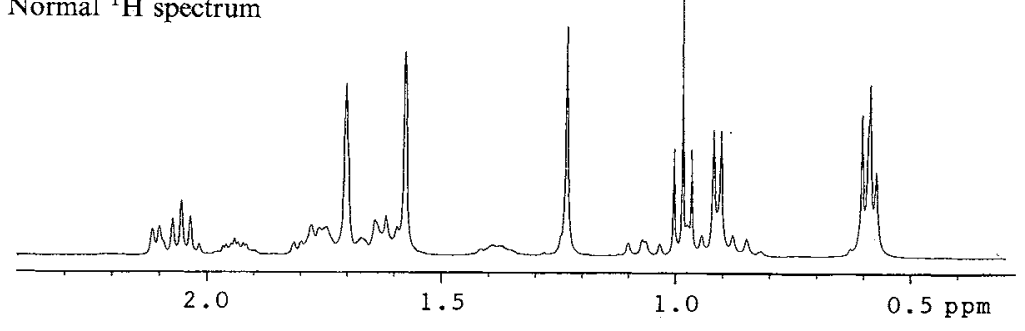

Fig. 7. Relative stereochemistry of the decalin ring by 1D-HOHAHA and NOEs.
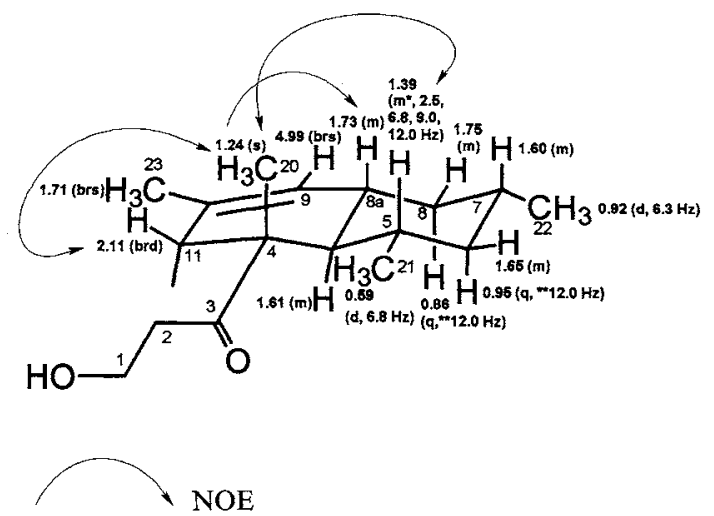

* These $J$ values were measured by spin decoupling; $\{0.59\}(21-\mathrm{H})$.

** These $J$ values were observed by 1D-HOHAHA; $\{0.59\}(21-\mathrm{H})$.

elemental analysis. The ${ }^{1} \mathrm{H}$ and ${ }^{13} \mathrm{C}$ NMR data of 3 are shown in Table 2 . These assignments were determined mainly by ${ }^{1} \mathrm{H}_{-}{ }^{13} \mathrm{C}$ COSY and 2D-HOHAHA spectra. By comparing with the NMR data of 2, methylene signals at $\delta 3.65$ and 3.92 were assigned to the hydroxymethyl group which was introduced by reduction of the aldehyde group. The fact that these protons $(1-\mathrm{H})$ coupled with $2-\mathrm{H}$ also confirmed the conversion of the aldehyde to the alcohol. The structure of $\mathbf{3}$ is shown in Fig. 1.

To determine the conformation of saturated part of the decalin ring (cyclohexane ring), the coupling constants of the cyclohexane ring should be determined. But the ${ }^{1} \mathrm{H}$-signals of the decalin moiety were overlapping as shown in Fig. 6. Therefore, a 1D-HOHAHA experiment and a spin decoupling experiment were performed to determine these coupling constants. Two quartets $(J=12.0 \mathrm{~Hz})$ of $8-\mathrm{H}_{\mathrm{ax}}(\delta 0.86)$ and $6-\mathrm{H}_{\mathrm{ax}}\left(\begin{array}{ll}\delta & 0.95\end{array}\right)$ were revealed by the 1D-HOHAHA experiment irradiating at $\delta 0.59$. In the spin decoupling experiment, irradiation at $\delta 0.59(21-\mathrm{H})$ caused the methine signal, $5-\mathrm{H}$ at $\delta 1.39$ (multiplet) 
to collapse to a readable signal of ddd $(J=12.0,9.0$ and $2.5 \mathrm{~Hz}$ ). Thus, the coupling constants between vicinal protons on the cyclohexane ring protons with the exception of those between two equatorial protons of methylene were all large. The large coupling constants suggested that the cyclohexane ring is in the chair conformation and the four methine protons on the cyclohexane ring are all axial; the junction of the decalin ring is trans and the two methyl groups $(\mathrm{C}-21, \mathrm{C}-22)$ are equatorial.

The conformation of the cyclohexene ring was determined by NOESY and NOE difference experiments. NOEs were observed between $5-\mathrm{H}$ and $20-\mathrm{H}, 8 \mathrm{a}-\mathrm{H}$ and $20-\mathrm{H}, 11-\mathrm{H}$ and $20-\mathrm{H}$. These NOEs, especially that observed between $8 \mathrm{a}-\mathrm{H}$ at the ring junction and $20-\mathrm{H}$ of the cyclohexene ring established the half-chair conformation for the cyclohexene ring. All of these results are summarized in Fig. 7.

\section{Geometry of the Double Bond}

The geometry of the double bond (C-16, C-17) was determined by NOE difference and NOESY spectra of the compound 3. NOEs observed between $15-\mathrm{H}$ and $17-\mathrm{H}, 25-\mathrm{H}$ and $18-\mathrm{H}$ established the geometry as $16 E$ as shown in Fig. 8.

Aldecalmycin was related to lydicamycin ${ }^{4)}$ on its planar structure described in the previous paper ${ }^{5)}$ but the ring system of aldecalmycin is not a type of lydicamycin but of diplodiatoxin ${ }^{6}$. The absolute configuration and biosynthesis of aldecalmycin will be described in accompanying papers ${ }^{7,8}$.

\section{Experimental}

General

MPs were determined on a Yanagimoto micro melting point apparatus. Optical rotations were measured with a Perkin-Elmer 241 polarimeter. IR spectra were recorded with a Hitachi I-5020 spectrometer. UV spectra were taken on a Hitachi U-3210 spectrometer. ${ }^{1} \mathrm{H}$ and ${ }^{13} \mathrm{C}$ NMR spectra were recorded on JEOL JNM-GX400 and JNM-EX270 spectrometers. Mass spectra were obtained with a JEOL JMS-SX102 spectrometer.

Preparation of Aldecalmycin Ethylene Ketal (2)

Aldecalmycin $(1,58.0 \mathrm{mg})$ and $\mathrm{D}$-camphorsulfonic acid $(5.8 \mathrm{mg})$ were dissolved in dioxane $(5.8 \mathrm{ml})$, to which was added ethylene glycol $(145 \mu \mathrm{l})$ and the reaction mixture was placed at $22^{\circ} \mathrm{C}$ for 23 hours. The mixture was concentrated in vacuo and the residue was dissolved with ethyl acetate $(40 \mathrm{ml})$. The solution was washed with saturated sodium bicarbonate aqueous solution $(20 \mathrm{ml})$. The solution was dried over anhydrous sodium sulfate and concentrated under reduced pressure to dryness. The residue was chromatographed on a silica gel column developed with EtOAc-MeOH $(15: 1)$ to give a white powder $(24.6 \mathrm{mg})$. This material was purified by a Sephadex LH-20 column chromatography with MeOH. Final purification was carried out on a centrifugal partition chromatography (CPC-L.L.N model NMF, Sanki Engineering Limited) with the solvent system, $n$-hexane- $\mathrm{MeOH}$, to give a white amorphous powder of 2 $(15.9 \mathrm{mg}$, yield; $25.6 \%)$.

Preparation of Dihydroaldecalmycin (3)

Aldecalmycin $(1,239 \mathrm{mg})$ was dissolved in $\mathrm{MeOH}(24 \mathrm{ml})$ in the presence of $\mathrm{AcOH}(120 \mu 1)$, to which was added sodium cyanoborohydride $(120 \mathrm{mg}$ ) and the reaction mixture was stirred at room temperature for 14 hours. The reaction mixture was concentrated under reduced pressure to dryness. The residue was 
dissolved in $\mathrm{MeOH}(1 \mathrm{ml})$ and applied to a Sephadex LH-20 column $(200 \mathrm{ml})$ and was eluted with $\mathrm{MeOH}$ to give a white amorphous powder of $3(205.4 \mathrm{mg}$, yield; $85.7 \%)$.

\section{References}

1) Sawa, R.; Y. TaKahashi, S. Itoh, K. Shimanaka, N. Kinoshita, Y. Homma, M. Hamada, T. Sawa, H. Naganawa \& T. TAKEUCH: Aldecalmycin, a new antibiotic from Streptomyces. I. Taxonomy, fermentation, isolation, physico-chemical and biological properties. J. Antibiotics 47: 1266 1272, 1994

2) Davis, D. G. \& A. BAx: Assignment of complex ${ }^{1} \mathrm{H}$ NMR spectra via two-dimensional homonuclear Hartmann-Harn spectroscopy. J. Am. Chem. Soc. 107: 2820 2821, 1985

3) BAx, A. \& M. F. Summers: ${ }^{1} \mathrm{H}$ and ${ }^{13} \mathrm{C}$ assignments from sensitivity-enhanced detection of heteronuclear multiple-bond connectivity by 2D multiple quantum NMR. J. Am. Chem. Soc. 108: 2093 2094, 1986

4) Hayakawa, Y.; N. Kanamaru, N. Morisaki, K. Furihata \& H. Seto: Lydicamycin, a new antibiotic of a novel skeletal type. II. Physico-chemical properties and structure elucidation. J. Antibiotics 44: 288 292, 1991

5) Sawa, R.; Y. Takahashi, S. Itoh, K. Shimanaka, N. Matsuda, M. Hamada, T. Sawa, H. Naganawa \& T. TAKEUCHI: Aldecalmycin, a new antimicrobial antibiotic from Streptomyces. J. Antibiotics 45: 136 139, 1992

6) Steyn, P. S.; P. L. Wessels, C. W. Holzapfel, D. J. J. Potgieter \& W. K. A. Louw: The isolation and structure of a toxic metabolite from Diplodia Maydis (Berk.) Sacc. Tetrahedron 28: 4775 4785, 1972

7) Sawa, R.; Y. Takahashi, H. Nakamura, K. T. Nakamura, H. Naganawa \& T. Takeuchi: Aldecalmycin, a new antimicrobial antibiotic from Streptomyces. III. Determination of absolute configuration. J. Antibiotics 47 : $1280 \sim 1283,1994$

8) Sawa, R.; Y. Takahashi, M. Hamada, T. Sawa, H. Naganawa \& T. Takeuchi: Biosynthesis of aldecalmycin. J. Antibiotics 47: 1351 1353, 1994 